\title{
In-orbit SAR Performance of TerraSAR-X
}

\author{
J. Márquez-Martínez, C. Gonzalez, M. Younis, S. Wollstadt, R. Metzig, \\ U. Steinbrecher, N. Tous-Ramon, A. Meta and J. Mittermayer \\ Microwaves and Radar Institute \\ German Aerospace Center (DLR) \\ Oberpfaffenhofen, Germany \\ E-mail: jose.marquez@dlr.de
}

\begin{abstract}
TerraSAR-X is the first German Radar satellite for scientific and commercial applications. The project is a publicprivate partnership between DLR and EADS Astrium GmbH. TerraSAR-X consists of a high resolution Synthetic Aperture Radar at $\mathrm{X}$-Band. The radar antenna is based on active phased array technology that allows the control of many different instrument parameters and operational modes (Stripmap, ScanSAR and Spotlight) with various polarizations.

Following the TerraSAR-X launch, it is planned a six month Commissioning Phase covering the characterization and verification of the SAR mission. Within this phase, the Overall SAR System Performance takes care of the correct working and interaction of all SAR system elements essential for obtaining an optimum SAR Performance.
\end{abstract}

The paper covers the first in-orbit characterization and verification results of the SAR system performance for
TerraSAR-X operational and experimental modes. This characterization is divided into four phases: Initial Characterization, Scene Characterization -both mostly based on basic and experimental products-, and Verification of TerraSAR$\mathrm{X}$ Instrument Command Generation.

The different optimization strategies and performance trade-offs are investigated and discussed, including very first TerraSAR-X images. The result of the real SAR data analysis determines the final system baseline and thus the final image quality, e.g. Temperature compensation, Total Zero Doppler Steering, Up/down chirp toggling, transmitted bandwidth, timing interferences, etc.

TerraSAR-X, Space-borne SAR; Performance Verification. 